\title{
Erratum to: Measuring and Monitoring Poverty and Well-Being: A New Approach for the Synthesis of Multidimensionality
}

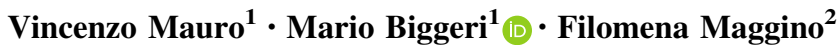

\section{Erratum to: Soc Indic Res}

\section{DOI 10.1007/s11205-016-1484-1}

Unfortunately, in the original publication of the article, the formula in Section 4 has been appeared incorrectly and the correct formula appears in this erratum.

$$
M S I_{i}=1-\left[\frac{1}{k} \sum_{j}\left(1-x_{i j}\right)^{g\left(x_{i}\right)}\right]^{\frac{1}{g\left(x_{i}\right)}}
$$

The online version of the original article can be found under doi:10.1007/s11205-016-1484-1.

Mario Biggeri

mario.biggeri@unifi.it

Vincenzo Mauro

vincenzo.mauro@unifi.it

Filomena Maggino

filomena.maggino@unifi.it

1 Department of Economics and Management, University of Florence, Via delle Pandette 9, 50127 Florence, Italy

2 Department of Statistics, University of Florence, Viale Morgagni, 59, 50134 Florence, Italy 